\title{
A Transfer Trip Scheme to Supervise Zone 3 Operation
}

\author{
J. Ganeswara Rao ${ }^{1}$ Ashok Kumar Pradhan ${ }^{1}$
}

Received: 25 April 2016/Accepted: 6 May 2016/Published online: 19 May 2016

(C) Indian National Academy of Engineering 2016

\begin{abstract}
Zone 3 of distance relay provides remote backup protection for adjacent transmission lines using local information. At times, zone 3 is prone to maloperation under stressed system conditions, which may cause serious threat to grid security. Zone 3 decisions can be more accurate, if fault pickup information of the adjacent line relays is availed. In this paper, zone 2 pickup signals of adjacent line relays are unified using simple logic gates and the information is transferred to supervise remote backup protection; the zone 3. Proposed method is tested for WSCC nine-bus and two-area four machine systems under different conditions and found to be accurate.
\end{abstract}

Keywords Backup protection - Distance relay $\cdot$ Logic gates $\cdot$ Transfer trip $\cdot$ Transmission line faults $\cdot$ Zone 3

\section{Introduction}

Zone 3 of distance relay is used as a backup protection for adjacent transmission lines when local protection fails to clear a fault (Anderson 1999). This protection component is prone to mal-operation during stressed system conditions like load encroachment, voltage instability and power swing. With deregulation, transmission elements are being operated at lower security margin to obtain economic benefit. A contingency under such conditions may cause undesirable operation of zone 3 and several such cases are reported in (Novosel et al. 2004) where zone 3

J. Ganeswara Rao ganeshjada@gmail.com

1 Department of Electrical Engineering, Indian Institute of Technology, Kharagpur, West Bengal 721302, India maloperations contributed to cascade tripping of transmission lines. Recently, zone 3 tripping of inter-regional tie line between Northern and Western regions due to load encroachment, led to grid collapse in India (PowerGrid 2012). In order to avoid such wrong operation, remote backup relay should able to distinguish stressed system condition from symmetrical fault.

Assessment of zone 3 with local backup protection is available in (Horowitz and Phadke 2006). Zone 3 provides complete redundancy in protection chain and therefore it is important. Zone 3 expansion caused by the contribution of in-feed fault current is quite significant because of which zone 3 coverage becomes larger. It restricts the load transfer through a transmission line under emergency conditions. While enhancing loadability of a line, secure operation of zone 3 can be ensured by modifying its characteristics (NERC Planning Committee 2006). An adaptive anti-encroachment zone is proposed in (Jin and Sidhu 2008) using steady-state security analysis. Such strategies result in compromising large fault coverage of the relay. Load blinders can be used to block the distance relay operation during heavy loading condition (Apostolov et al. 2004). Obtaining settings to discriminate high resistance fault from heavy load with low power factor is difficult.

Zone 3 is also vulnerable to power swing and voltage instability conditions. Power swing blocking (PSB) function is provided in distance relay to avoid such unwanted tripping during power swing (IEEE PSRC Report 2005). To obtain correct PSB settings is challenging and require huge off line studies. An adaptive algorithm using rate of change in voltage is proposed in (Jonsson and Daalder 2003) to supplement distance relay decision during voltage instability. A support vector machine tool is used in (Seethalekshmi et al. 2012) to supervise the distance relay by segregating fault, power swing and voltage instability. 
Recent development in digital, communication technology and time synchronization of relays using global position system (GPS) has enabled in harvesting large area information to support relay decision. Impedance calculated from synchrophasor data is applied to support zone 3 decision (Kundu and Pradhan 2014). A wide-area backup expert protection system is proposed in (Tan et al. 2002), using relay pickup information from multiple substations.

In pilot protection, relay pickup information is being transferred to other ends using communication channel to accelerate protection decision (Yalla et al. 2002). Such a technique is exploited in this paper to supervise zone 3 decision. Zone 2 pickup signals of adjacent line relays are unified using simple logic gates and transferred using pilot communication to distinguish stressed system condition from symmetrical fault. Proposed method is tested for WSCC nine-bus and two-area four machine systems under symmetrical fault and stressed system conditions simulated using PSCAD/EMTDC software.

\section{Proposed Method}

For any fault in a transmission line, distance relays of a faulty line and remote backup relays placed in adjacent line detect it in their respective zone characteristics. Whereas during stressed system condition, the impedance trajectory do not enter inside the operating zones of all the relays (Kundu and Pradhan 2014). A supervised zone 3 decision is developed based on above criterion utilizing zone 2 pickup signals of adjacent line relays.

In a radial transmission system shown in Fig. 1, distance relays $R_{M N}, R_{N M}, R_{N P}$, and $R_{P N}$ are placed at bus $M, N$, and $\mathrm{P}$ for line protection. Second zone of the distance relays is set to cover $100 \%$ of the line. Thus for any fault in line-2, both $\mathrm{R}_{\mathrm{NP}}$ and $\mathrm{R}_{\mathrm{PN}}$ relays will detect it in their zone 2. In order to protect the adjacent transmission line, zone 3 setting of relay $R_{M N}$ for the radial transmission system (refer Fig. 1) is determined as $Z_{\mathrm{MN}}+1.2 \mathrm{Z}_{\mathrm{NP}}$ where, $Z_{M N}$ and $Z_{N P}$ are line impedances of line-1 and -2, respectively. This setting may not suitable for multiple lines connected at bus $\mathrm{N}$. Relay $\mathrm{R}_{\mathrm{MN}}$ may under reach for a

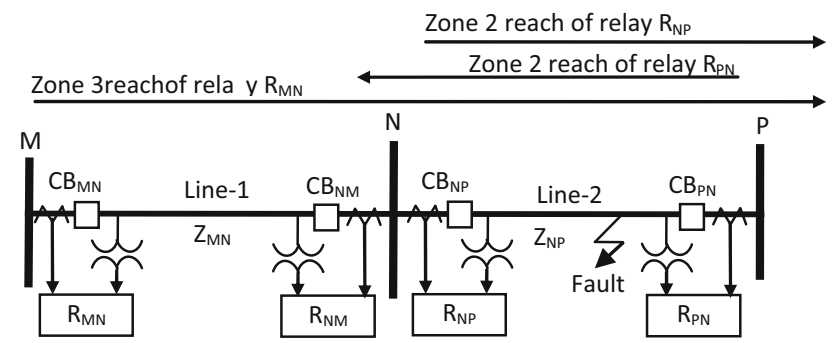

Fig. 1 The three bus radial transmission system

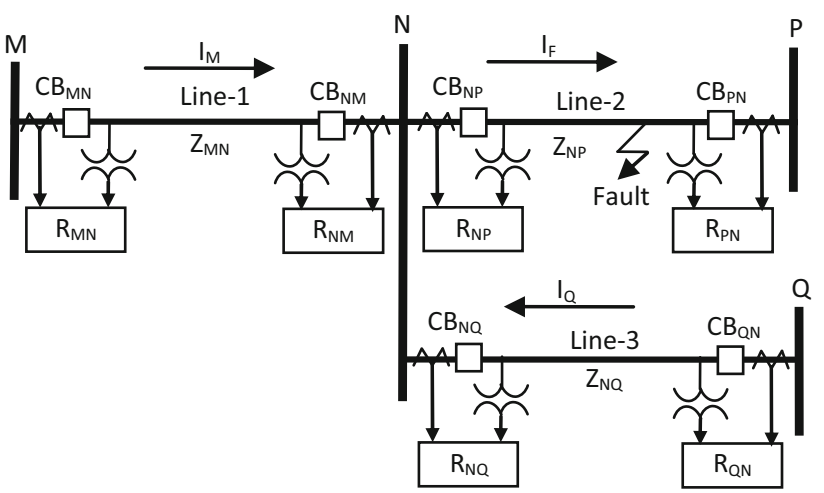

Fig. 2 The four bus transmission system

fault in line-2, due to fault current contribution from line-3 $\left(\mathrm{I}_{\mathrm{Q}}\right)$ as shown in Fig. 2. In order to provide backup protection for entire line, zone 3 setting of relay $R_{M N}$ should be modified considering the in-feed current from line-3 as follows (Horowitz and Phadke 2006),

Zone 3 of relay $\mathrm{R}_{\mathrm{MN}}=\mathrm{Z}_{\mathrm{MN}}+1.2 \mathrm{Z}_{\mathrm{NP}}\left(1+\frac{\mathrm{I}_{\mathrm{Q}}}{\mathrm{I}_{\mathrm{M}}}\right)$

where, $\mathrm{I}_{\mathrm{M}}$ and $\mathrm{I}_{\mathrm{Q}}$ are fault current flowing through line-1 and 3 , respectively. As a result, zone 3 characteristic becomes larger and closer to the load impedance.

During a stressed condition, the apparent impedance may fall inside zone 3 of $\mathrm{R}_{\mathrm{MN}}$ which has a larger coverage. However, all the six relays do not find the apparent impedances in their operating zones simultaneously during such a stressed condition (Kundu and Pradhan 2014). In general, zone 2 is away from the load impedance and the effect of in-feed is not significant for zone 2 compared to zone 3 . Thus, zone 2 is considered more secured than zone 3 during stressed system condition (Horowitz and Phadke 2006). Such reliable zone 2 pickup information of adjacent line relays is utilized to assist zone 3 decision of remote backup relay in distinguishing symmetrical fault from stressed system condition.

\section{Trip Signal for Zone 3 Supervision}

Sharing the information in between the relays using communication system can enhance the overall protection of the power system (IEEE PSRC Report 2008). Zone 2 pickup information at each end of a line is being transferred in Permissive Overreaching Transfer Trip (POTT) scheme using pilot communication (Yalla et al. 2002). In such scheme, both zone-2 decision signals of line-2 relays $\mathrm{R}_{\mathrm{NP}}$ and $\mathrm{R}_{\mathrm{PN}}$ (their decision signals $\mathrm{S}_{1}$ and $\mathrm{S}_{1}^{\prime}$, respectively) and line-3 relays $\mathrm{R}_{\mathrm{NQ}}$ and $\mathrm{R}_{\mathrm{QN}}$ (their decision signals $\mathrm{S}_{2}$ and $\mathrm{S}_{2}^{\prime}$, respectively) are available at bus-N and $\mathrm{P}$ 


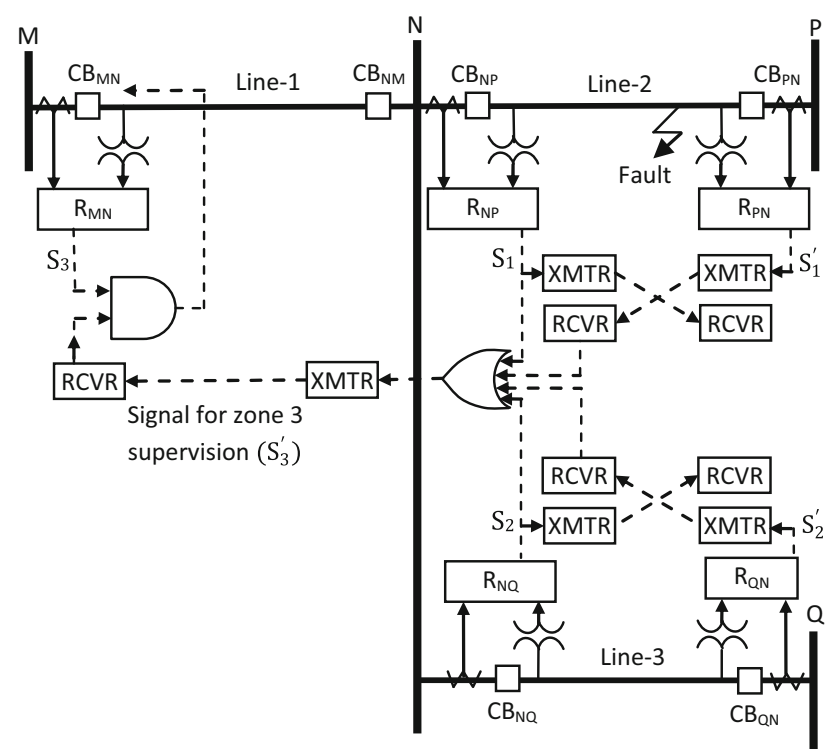

Fig. 3 The four bus transmission system for zone 3 supervision

as illustrated in Fig. 3. At bus-N, unifying zone 2 pickup signals of line-2 and line-3 relays using OR logic, a supervised trip signal $\left(S^{\prime}{ }_{3}\right)$ is developed for $R_{M N}$.

$\mathrm{S}_{3}^{\prime}=\mathrm{S}_{1} \mathrm{~V} \mathrm{~S}_{1}^{\prime} \mathrm{VS}_{2} \mathrm{~V} \mathrm{~S}_{2}^{\prime}$

where, ' $\mathrm{V}$ ' indicates logical OR operation. It can be transferred to bus $\mathrm{M}$ using pilot communication for supervising zone 3 decision of relay $\mathrm{R}_{\mathrm{MN}}\left(\mathrm{S}_{3}\right)$. The backup protection scheme initiates trip decision for circuit breaker $\mathrm{CB}_{\mathrm{MN}}$ only when both $\mathrm{S}_{3}$ and $\mathrm{S}_{3}^{\prime}$ are triggered.

\section{Communication Issues}

In the proposed method the relay pickup information of the adjacent lines, need to be communicated to remote backup relay as demonstrated in Fig. 3 for line-1. Being binary signals, the bandwidth requirement of communication system is very low. Zone 3 decision is a delayed protection decision; communication delay is not an issue for this method with the present technology. Power lines, telephone lines, microwave and fiber-optic cables can be used as communication medium for the purpose (Yalla et al. 2002), (IEEE PSRC Report 2008). Since the proposed method depends on communication channel, the method should be disabled during communication failures. Few pilot communication health-monitoring techniques are available in (IEEE PSRC Report 2008).

\section{Results}

The $230 \mathrm{kV}, 60 \mathrm{~Hz}$, WSCC nine-bus and two-area four machine systems are used to test the effectiveness of the proposed method. The systems are simulated in PSCAD/
EMTDC software considering detailed model for generators and distributed parameter model for lines. Distance relays are assumed to be available for line protection. Mho relay characteristics having zone 1 setting $80 \%$ and zone 2 setting $120 \%$ of the line impedance and zone 3 covering longest adjacent line are considered.

\section{Results for WSCC 9-Bus System}

First the $230 \mathrm{kV}, 60 \mathrm{~Hz}$, WSCC nine-bus power system as shown in Fig. 4 is considered. With one communication link capable of transmitting one bit information, each line requires four links ( 2 for zone 2 pickup, 2 for zone 3 supervision) therefore, WSCC nine-bus system requires 24 links $(4 \times 6)$ for implementation of this method. The outputs of current transformer of 300:5 and voltage transformer of $230 \mathrm{kV}: 110 \mathrm{~V}$ are fed to the relay. Relay $R_{75}$ at bus 7 is considered as backup relay for line 4-5. Zone 2 pickup signals of relays $R_{45}$ and $R_{54}$ are used to supervise the zone 3 decision of relay $R_{75}$. Results for power swing and symmetrical fault cases are provided.

\section{Power Swing Case}

Sudden change of line flow in power system causes oscillations in rotor angles, voltage and current magnitudes. During this period, apparent impedance of a distance relay may enter inside its operating zones. Zone 3 is more vulnerable to misoperate even during stable power swing and may trip healthy line that deteriorates the stability of the system. Most of the swings are stable in nature aroused by minor disturbances, which are quite common in power system. Such a scenario is simulated by initiating a three-

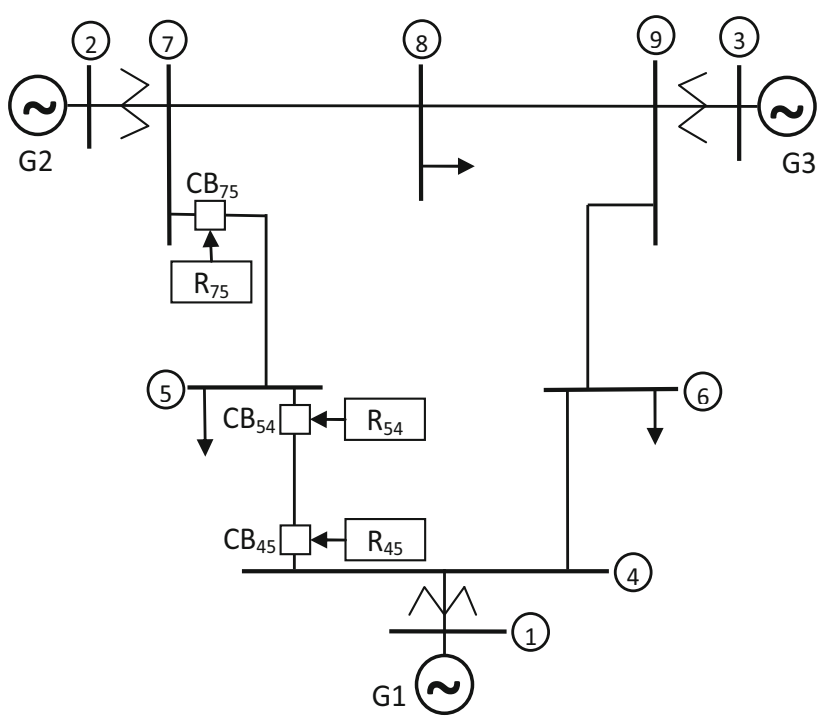

Fig. 4 The WSCC 9-bus power system 


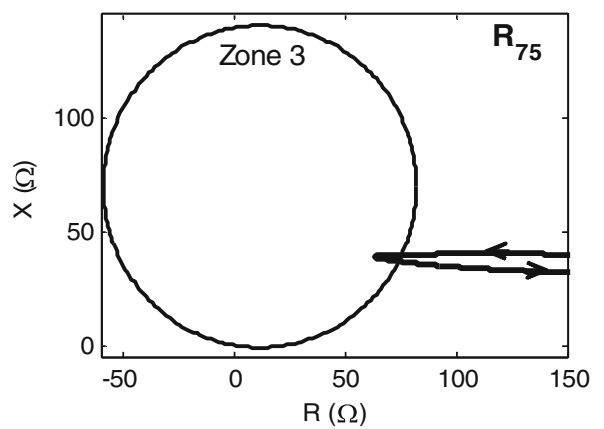

(a)

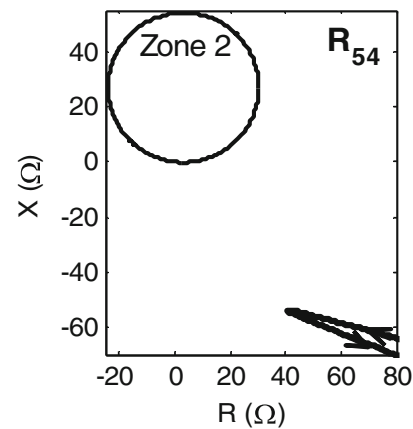

(b)

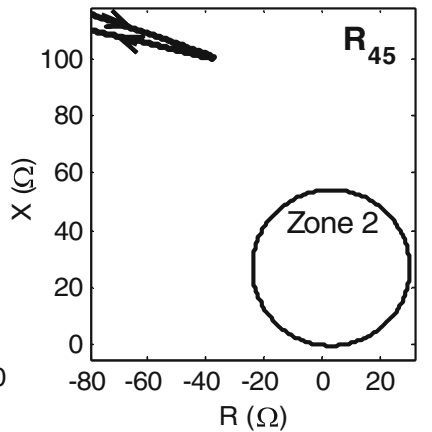

(c)
Fig. 5 Results for power swing case a Impedance trajectory of $R_{75}$ b Impedance trajectory of $R_{54}$ Impedance trajectory of $R_{45}$

phase fault on line 9-6, which is isolated by opening the line breakers after 8 cycles. As a result, the apparent impedance of relay $R_{75}$ is inside zone 3 as shown in Fig. 5a and it may trip line 7-5 unnecessarily. Under such circumstances, proposed method is useful to block $\mathrm{R}_{75}$ operation using adjacent line relays pickup signals. Since apparent impedance of line 4-5 relays $R_{54}$ and $R_{45}$ are outside zone 2 as shown in Fig. 5b, c, supervising trip signal is not enabled for $\mathrm{R}_{75}$. Thus, the method provides a correct decision.

\section{Symmetrical Fault Case}

In order to test the proposed method for which zone 3 is intended to operate; a three-phase fault is simulated at $80 \%$ of the line length from bus 5 in line 4-5. In this case, relay $R_{54}$ is unable clear the fault due to its battery failure.

When a battery fails, the connected protection system will not work even with receipt of direct trip signal from the other end. Under such circumstance backup relay $R_{75}$ should clear the fault. The impedance seen by backup relay $\mathrm{R}_{75}$ and primary distance relay $\mathrm{R}_{45}$ are shown in Fig. $6 \mathrm{a}, \mathrm{b}$ respectively. Relay $R_{75}$ finds the fault in zone 3 as shown in Fig. $6 a$ and it needs confirmation of fault in adjacent line section. The apparent impedance of relay $R_{45}$ is inside zone 2 as noticed from Fig. $6 \mathrm{~b}$ and ensured the fault is in line 4-5. Failure of both end relay elements of line $4-5\left(R_{54}\right.$ and $\left.R_{45}\right)$

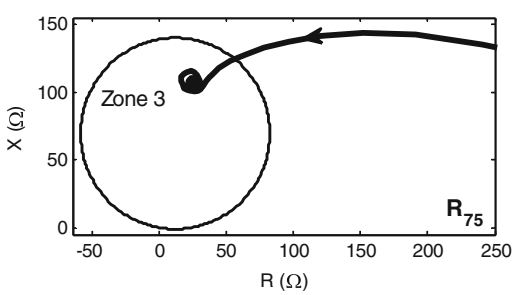

(a)

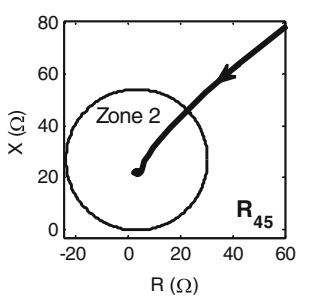

(b)
Fig. 6 Results for symmetrical fault case a Impedance trajectory of $\mathrm{R}_{75}$ b Impedance trajectory of $\mathrm{R}_{45}$

simultaneously is certainly rare. The supervised trip signal is enabled for $\mathrm{R}_{75}$ to clear the fault from bus 7 . This case clearly shows the impedance trajectories of both primary and backup relays see the impedance in their respective zone characteristics during fault situation. Communicating fault pickup information of adjacent line relays can improve the zone 3 decision of remote backup relay.

\section{Results for Two-Area Four Machine System}

The proposed method is also tested for $230 \mathrm{kV}, 60 \mathrm{~Hz}$, two-area four machine power system as shown in Fig. 7. The outputs of current transformer of 600:5 and voltage transformer with ratio of $230 \mathrm{kV}: 110 \mathrm{~V}$ are fed to the relay. Relay $R_{1}$ in line- 1 at bus- 7 is considered as backup relay for line-3 and 4 . Zone 2 pickup signals of adjacent line relays are used to supervise the zone 3 decision of $R_{1}$.

\section{Load Encroachment Case}

When a line gets overloaded during contingency, the impedance seen by distance relay may enter zone 3 and remain inside the characteristic. It causes unwanted tripping of the healthy line. A load encroachment scenario is simulated by assuming line- 2 is out of service and gradual shifting of 380 MVA, 30 MVAR load from bus 7 to 8 . As a result, line-1 gets overloaded and the load impedance is inside zone 3 of relay $R_{1}$ as seen from Fig. 8a, and it may trip line-1 unnecessarily. Under such circumstances, proposed method is useful to block $R_{1}$ operation using adjacent line relays pickup signals. Since apparent impedance of line- 2 and 3 relays $R_{5}, R_{6}, R_{7}$, and $R_{8}$ are outside zone 2 as observed from Fig. 8b, c, supervising trip signal is not enabled for $R_{1}$. Thus proposed method provides correct zone 3 decision for the situation.

\section{Conclusion}

The fault pickup signals of the adjacent line relays are unified and made available to the remote backup relay to supervise zone 3 decision. The method avails the required 


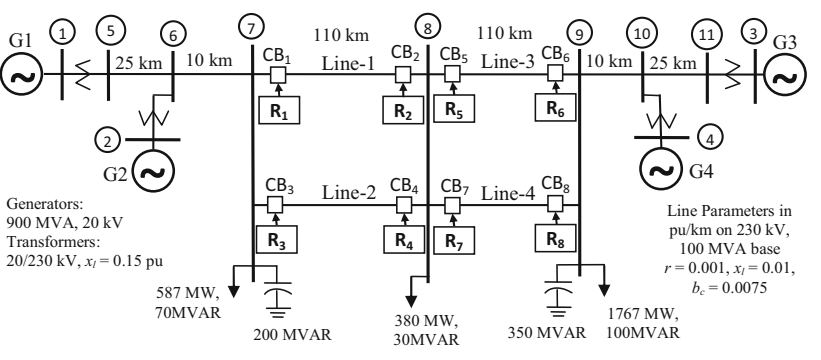

Fig. 7 The two-area four machine power system

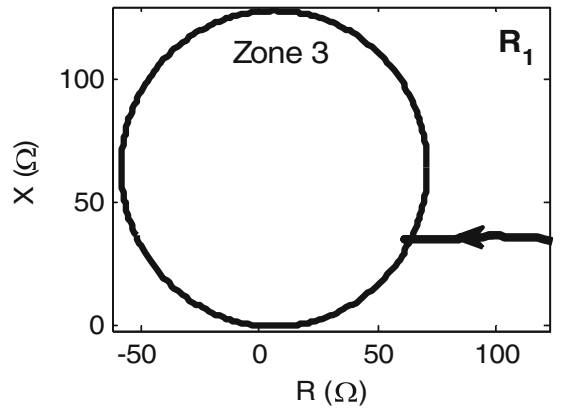

(a)

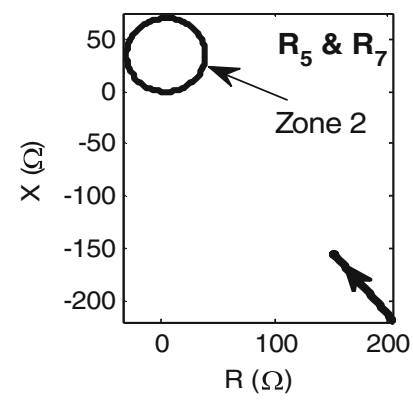

(b)

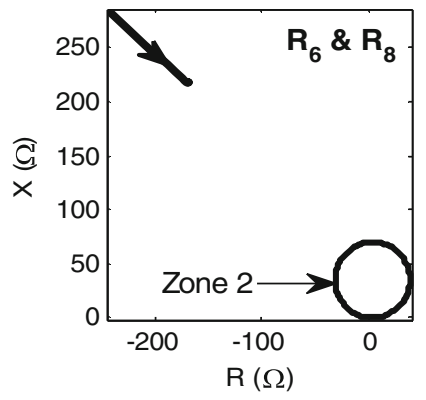

(c)
Fig. 8 Results for load encroachment case a Impedance trajectory of $R_{1} b$ Impedance trajectory of $R_{5}$ and $R_{7} c$ Impedance trajectory of $R_{6}$ and $\mathrm{R}_{8}$

signals through communication facility, which is feasible with present technology. No threshold setting or major calculation is required for the method. The proposed method is tested for WSCC nine-bus and two-area four machine systems during symmetrical fault and stressed system condition. Found that communicating fault pickup information of adjacent line relays can provide improved zone 3 decision for remote backup protection.

\section{References}

Anderson PM (1999) Power system protection. IEEE Press Power Engineering Series, New York

AP Apostolov, D Tholomier, SH Richards (2004) Distance protection and dynamic loading of transmission lines. IEEE Power Eng Society General Meet, p 100-105

Horowitz SH, Phadke AG (2006) Third zone revisited. IEEE Trans on Power Del 21(1):23-29

IEEE Power System Relaying Committee (2005) Power swing and out-of-step considerations on transmission line, Rep PSRC WG D6. Available: http://www.pes-psrc.org

IEEE Power System Relaying Committee (2008) Justifying pilot protection on transmission lines, Rep. PSRC WG D8

Jin M, Sidhu TS (2008) Adaptive load encroachment prevention scheme for distance protection. Elect Power Sys Res 78(10):1693-1700

Jonsson M, Daalder JE (2003) An adaptive scheme to prevent undesirable distance protection operation during voltage instability. IEEE Trans Power Del 18(4):1174-1180

Kundu P, Pradhan AK (2014) Synchrophasor-assisted zone 3 operation. IEEE Trans Power Del 29(2):660-667

NERC Planning Committee (2006) Methods to increase line relay loadability, System Protection and control Task Force of the NERC Planning Committee

Novosel D, Begovic M, Madani V (2004) Shedding light on blackouts. IEEE Power Energ Mag 2(1):32-43

PowerGrid (2012) Report of the enquiry committee on grid disturbance in northern region on 30th July 2012 and in northern, eastern and north-eastern region on 31st July 2012, New Delhi, India, Tech. Rep. GRID_ENQ_REP_16_8_12

Seethalekshmi K, Singh SN, Srivastava SC (2012) A classification approach using support vector machines to prevent distance relay maloperation under power swing and voltage instability. IEEE Trans Power Del 27(3):1124-1133

Tan JC, Crossley PA, McLaren PG, Hall I, Farrell J, Gale P (2002) Sequential tripping strategy for a transmission network back-up protection expert system. IEEE Trans Power Del 17(1):68-74

Yalla M et al (2002) Application of peer-to-peer communication for protective relaying. IEEE Trans Power Del 17(2):446-451 